\title{
Factors associated with wound healing outcome among Diabetic Foot patients- A cross sectional Study
}

\author{
M. Jayalakshmi ${ }^{1 *}$, P. Thenmozhi ${ }^{2}$ \\ ${ }^{1}$ Research Scholar, Saveetha Institute of Medical and Technical Sciences, Chennai, Tamil \\ Nadu and Army Institute of Nursing, Gauhati, Assam, India. \\ ${ }^{2}$ Associate professor, Saveetha Institute of Medical and Technical science, Chennai, Tamil \\ Nadu, India.
}

\begin{abstract}
:
Diabetic foot ulcer (DFU) has been identified as the leading reason for hospitalization among patients with diabetes. Patients with diabetes are at greater risk of complications, the most important of them are diabetic neuropathy and peripheral vascular disorders leading to the development of foot ulcers. The problem is generally faced and as well is considered as one among the most common complications of diabetes that affect millions of people all over the world. The current study, aimed to document the clinical profile and healing outcome of diabetic foot ulcer management which may become guidance for further improvement in wound management among diabetic foot ulcer patients. Cross sectional descriptive study was conducted over one-year period of time. A total of 246 Diabetic patients with a foot ulcer of Grade 1 to 3 participated in the study. Patients with higher grade ulcers of Grade 4 and 5 were excluded from the study. Final data analysis of 160 patients was done using SPSS version 20. The prevalence of Grade 2 and 3 ulcers were observed $54.37 \%$ and $31.8 \%$ while Grade 1 ulcer was observed $13.75 \%$. No risk factors were found to be significantly associated with diabetic foot ulcer. Wound was healed well in $50 \%$ and partially healed in $21 \%$ of the participants. Wound remains unchanged in $3 \%$ of study participants, while $8 \%$ of participants underwent toe amputation. Foot ulceration is a preventable in many diabetic patients with adequate education, routine foot care and attention to foot wear.
\end{abstract}

Keywords: Diabetic Foot Ulcer, Healing outcome, Nursing assessment, Risk factors.

\begin{tabular}{c|l|}
\hline Received: 17.11.2020 & Revised: 07.02.2021 Accepted: 19.03.2021 \\
\hline Quick Response code & $\begin{array}{l}\text { *CORRESPONDING AUTHOR: } \\
\text { Dr. M. Jayalakshmi, } \\
\text { Research Scholar, Saveetha Institute of Medical } \\
\text { and Technical Sciences, } \\
\text { Army Institute of Nursing Gauhati, Assam. } \\
\text { Email: jaya1807@ yahoo.in }\end{array}$ \\
\hline
\end{tabular}




\section{Introduction:}

Diabetes is a chronic metabolic disorder of multiple etiology, ${ }^{[1]}$ an epidemic problem that has exploded all over the world. [2] Globally, rates of diabetes and other metabolic diseases have exploded over the last several decades. ${ }^{[3]}$ Worldwide, more than 170 million individuals currently suffer from diabetes, and this number is projected to reach a staggering 366 million by $2030 .^{\text {[2] }}$ India, with 69.2 million people with T2DM, is the country with $2^{\text {nd }}$ highest number of people living with diabetes mellitus worldwide next to China. ${ }^{[4]}$ Patients with diabetes are at greater risk of complications, the most important of them are diabetic neuropathy and peripheral vascular disorders that lead to diabetic foot ulcers. "5] "It is a common problem and as well is one of the most common complications of diabetes that affect millions of people all over the world. [6] As the diabetes epidemic continues to spread, it is logic to anticipate a rise in complications like DFU in the absence of well articulate strategies that are executed at all levels. ${ }^{[7]}$ The global prevalence of DFU was $6.3 \%$ and was higher in type 2 diabetes $(6.4 \%)$ than type 1 diabetes $(5.5 \%) .{ }^{[6]} \mathrm{DFU}$ has been identified as the leading reason for hospitalization among patients with diabetes.

The life time risk of DFU in a person living with diabetes is $15 \%$ which rise up to $25 \%$. [7] The annual incidence of diabetic foot ulcer (DFU) in diabetic patients is known to be about $2 \%$ to $5 \%$. ${ }^{[8]}$ The ulceration and/or destruction of soft tissue of the feet of individuals with diabetes characterize a clinical condition commonly known as the diabetic foot ulceration (DFU), responsible for $20 \%$ of all hospitalizations of people with DM. ${ }^{[11]}$ Foot ulcers not only affect the productivity and quality of life, can create adverse impact on healthcare delivery system and health economics. The progressive rise of diabetes is likely to pose a significant burden on future society leading to an associated increase in diabetic amputations. Prevention of lower limb amputations may be the most effective way to reduce the high cost. ${ }^{[9]}$

Multiple risk factors are associated with the development of DFU which include gender (male), duration of diabetes longer than 10 years, advanced age of patients, and other co-morbidities such as retinopathy, diabetic peripheral neuropathy, peripheral vascular disease, glycated hemoglobin level (HbA1C), foot deformity, high plantar pressure, infections, and inappropriate foot self-care habits. ${ }^{[10]}$ It is seen that poor clinical outcomes are generally associated with infection, peripheral vascular disease, and increasing wound depth; it also appears that the progressive cumulative effect of these comorbidities contribute to a greater likelihood of a diabetic foot ulcer leading to a lower-limb amputation. ${ }^{[1]}$ The current study, aimed to document the clinical profile and outcome of diabetic foot ulcer management which may become a guidance for wound management among diabetic foot ulcer patients.

\section{Materials \& Methods:}

The study was conducted among diabetic foot ulcer patients who attended the foot care clinic at a Sun Valley Hospital located 
within Guwahati, the capital city of Assam, in Eastern part of India. It is a private, super specialty hospital for diabetics. This crosssectional descriptive study was conducted over one-year period of time between Feb 2019 and Feb 2020. Type I and II Diabetic mellitus patients with a foot ulcer of Grade 1 to 3 participated in the study as per Wagner classification. Diabetic patients with higher grade ulcers of Grade 4 and 5 were excluded from the study.

\section{Participants enrolled $=246$}

Excluded from study
$\quad=46$
(higher Grade ulcer,
declined to participate,
other reasons)
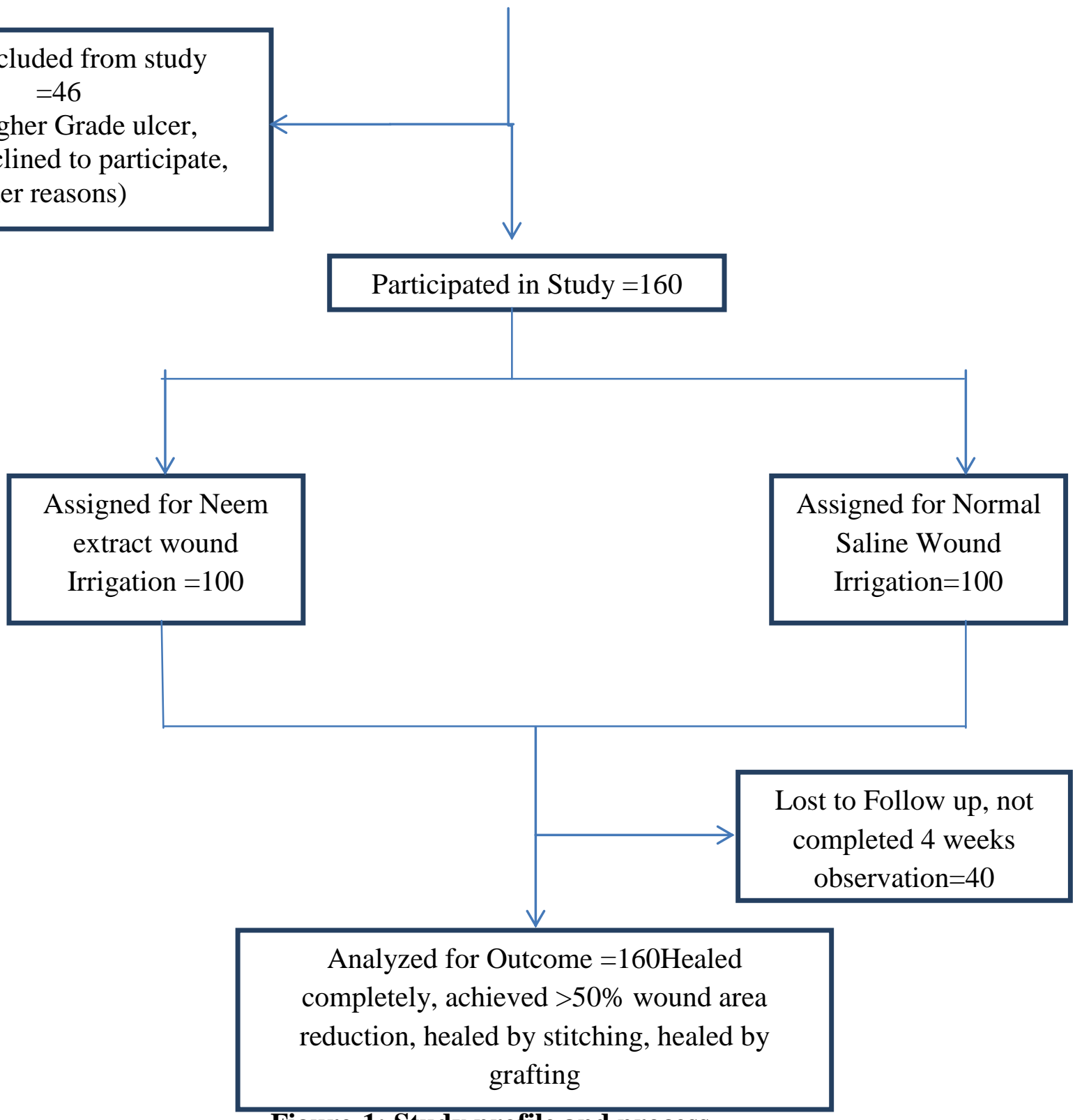

Figure-1: Study profile and process 


\section{Sample size determination and selection of patients}

Based on pilot study, ${ }^{[32]}$ sample size was calculated to have 80 participants in each group. Considering the attrition rate, 100 participants were assigned randomly in each of the 2 groups. The inclusion criteria were patients with minimum18 years of age, having confirmed diagnosis of diabetes mellitus, able to walk, having a support of a family member. The exclusion criteria were patients with severe disabling disease or systemic infection, or inability to walk, severe mental illness preventing informed consent, and patients with Grade 4 or 5 ulcers as per Wagner Scale. The wound care procedure was explained to all patients, and written informed consent was completed and signed by all of them at the first visit. Base line information of the participants included such as age, sex, marital status, educational level, employment status, smoking status, diabetes duration, type of diabetes treatment (oral antidiabetic agents or use of injection insulin), cause of present foot ulcer, and awareness on self - foot care practices.

All participants were then assessed by the researcher for the presence of type of abnormal blood pressure, condition of skin and nails of the affected limb, types of foot deformity, loss of protective sensation, wearing ill-fitting shoe. Vascular status of the lower limb was examined by the researcher by feeling of the presence of dorsalis pedis and tibialis posterior pulses, color of the limb. DFU was defined as a full thickness skin defect at least Wagner stage 1. ${ }^{[12]}$ participant's HbA1c and blood sugar random level was measured. HbA1c of lower than $7 \%$ was considered as good glycemic control. ${ }^{[13]}$ Participants of the study were followed up for the healing process and outcome in terms of completely healed, healed well $(\geq 50 \%$ reduction in wound area at the completion of four weeks), slow healing $(<50 \%$ reduction in wound area at the completion of four weeks), healed by stitching, grafting and minor amputation (toe amputation).

\section{Analysis}

Data were analyzed using SPSS version 20. To describe the variables, mean $\pm \mathrm{SD}$ was used for continuous data, and frequency and percentage were used for categorical data. Chi Square test was used to identify the statistically significant risk factors, where $\mathrm{p}$ value $\leq .05$ was considered as significant.

\section{Ethical considerations}

Prior to the commencement of the study, ethical clearance was obtained from the hospital authority CDSCO, Govt of India vide Regd. No. ECR /487/Inst/AS/2013/ RR-16.

\section{Results:}

\section{Clinical characteristics of patients}

There were 160 patients with diabetic foot problems who have completed 4 weeks study participation, out of which 131(77\%) were males and 29(23\%) were females. Patients (99.4 \%) had type-2 diabetes mellitus, age ranged between 22 and 80 years. The average duration of diabetes was 11.5 years for both groups. The mean $\mathrm{HbA1c}$ at the time of admission was $10.69 \pm$ $2.9 \%$. Common precipitating events of 
ulcers, found in this study included minor trauma, walking barefoot, spontaneous blisters, and ill-fitting shoes. It was found that in $48.75 \%$ of patients, the cause of developing foot ulcer was unknown to them. In this study, 22(13.75\%), 87(54.37\%),51 $(31.87 \%)$ patients were in grade1,2,3 of
Wagner scale respectively. Mild or Moderate infection was present in nearly $146(91.25 \%)$ of all patients, while $14(8.75 \%)$ patients had no sign of infection. Almost all participants were not aware of self-foot care practices.

Table-1: Clinical characteristics of participants at baseline:

\begin{tabular}{|c|c|c|c|c|}
\hline Risk factors & $\begin{array}{l}\text { Experimental } \\
\text { group }\end{array}$ & $\begin{array}{l}\text { Control } \\
\text { group }\end{array}$ & $\begin{array}{l}\text { Chi Square } \\
\text { value }\end{array}$ & p value \\
\hline $\begin{array}{l}\text { Smoking habit of patients } \\
\text { Non-Smoking } \\
\text { Past habits of smoking } \\
\text { Smoking } \\
\text { long term smoking }\end{array}$ & $\begin{array}{l}71 \\
9 \\
0 \\
0\end{array}$ & $\begin{array}{l}72 \\
3 \\
1 \\
4\end{array}$ & 8.007 & $0.046^{*}$ \\
\hline $\begin{array}{l}\text { Medications used by patients } \\
\text { Insulin } \\
\text { Oral Hypoglycemic drug } \\
\text { Insulin + OHA } \\
\text { No medications }\end{array}$ & $\begin{array}{l}48 \\
21 \\
11 \\
0\end{array}$ & $\begin{array}{l}53 \\
9 \\
10 \\
8\end{array}$ & 13.095 & $0.004 * * *$ \\
\hline $\begin{array}{l}\text { Years of DM in patients } \\
<5 \text { years } \\
5.1-15 \text { years } \\
\text { 15.1-25years } \\
>25 y e a r s\end{array}$ & $\begin{array}{l}29 \\
28 \\
18 \\
5\end{array}$ & $\begin{array}{l}23 \\
26 \\
20 \\
11\end{array}$ & 4.55 & $0.0335^{*}$ \\
\hline $\begin{array}{l}\text { Loss of Perception sensation } \\
\text { Yes } \\
\text { No }\end{array}$ & $\begin{array}{l}34 \\
46\end{array}$ & $\begin{array}{l}36 \\
44\end{array}$ & 0.626 & $0.429 *$ \\
\hline $\begin{array}{l}\text { Presence of Pedal Pulses } \\
\text { Yes } \\
\text { No }\end{array}$ & $\begin{array}{l}78 \\
2\end{array}$ & $\begin{array}{l}71 \\
9\end{array}$ & 3.51 & $0.060 *$ \\
\hline
\end{tabular}

$* * *$ Highly Significant, $\mathrm{p}<.01, * *$ Significant, $\mathrm{p}<.05, *$ Not Significant, $\mathrm{p}>.05$ 
INTERNATIONAL JOURNAL OF AYUSH CASE REPORTS (IJA-CARE)

Table 2: Bacteria most frequently present at baseline in Experimental and Control Groups.

\begin{tabular}{|l|l|c|c|}
\hline Organism & Gram Stain & $\begin{array}{c}\text { Experimental } \\
(\mathbf{n})\end{array}$ & $\begin{array}{c}\text { Control } \\
(\mathbf{n})\end{array}$ \\
\hline Nil Organism & & 43 & 36 \\
\hline Acinotobactor baumannii & Gram Negative & 2 & 2 \\
\hline Citrobacter koseri & Gram Negative & 0 & 1 \\
\hline Escherichia coli & Gram Negative & 3 & 8 \\
\hline Klebsiella pneumoniae & Gram Negative & 11 & 13 \\
\hline Pseudomonos aeruginosa & Gram Negative & 4 & 4 \\
\hline Proteus mirabilis & Gram Negative & 1 & 3 \\
\hline Streptococcus agalactice & Gram Positive & 4 & 8 \\
\hline Esterococcus faecalis & Gram Positive & 1 & 3 \\
\hline Streptococcus hemolyticus & Gram Positive & 0 & 3 \\
\hline Staphyloccus aureus & Gram Positive & 11 & 5 \\
\hline
\end{tabular}

A total of 146 specimens were cultured at base line which yielded 87 positive cultures (60\%). Thirteen samples were polymicrobial infection with a total 10 isolates recovered that included 10 bacterial and no fungal organisms were isolated (Table 2). Among the positive-cultured specimen, Gram-negative bacilli constituted the majority (68.85\%). Klebsiella Pneumoniae was found to be the most common isolates, followed by Staphylococcus Aureus.

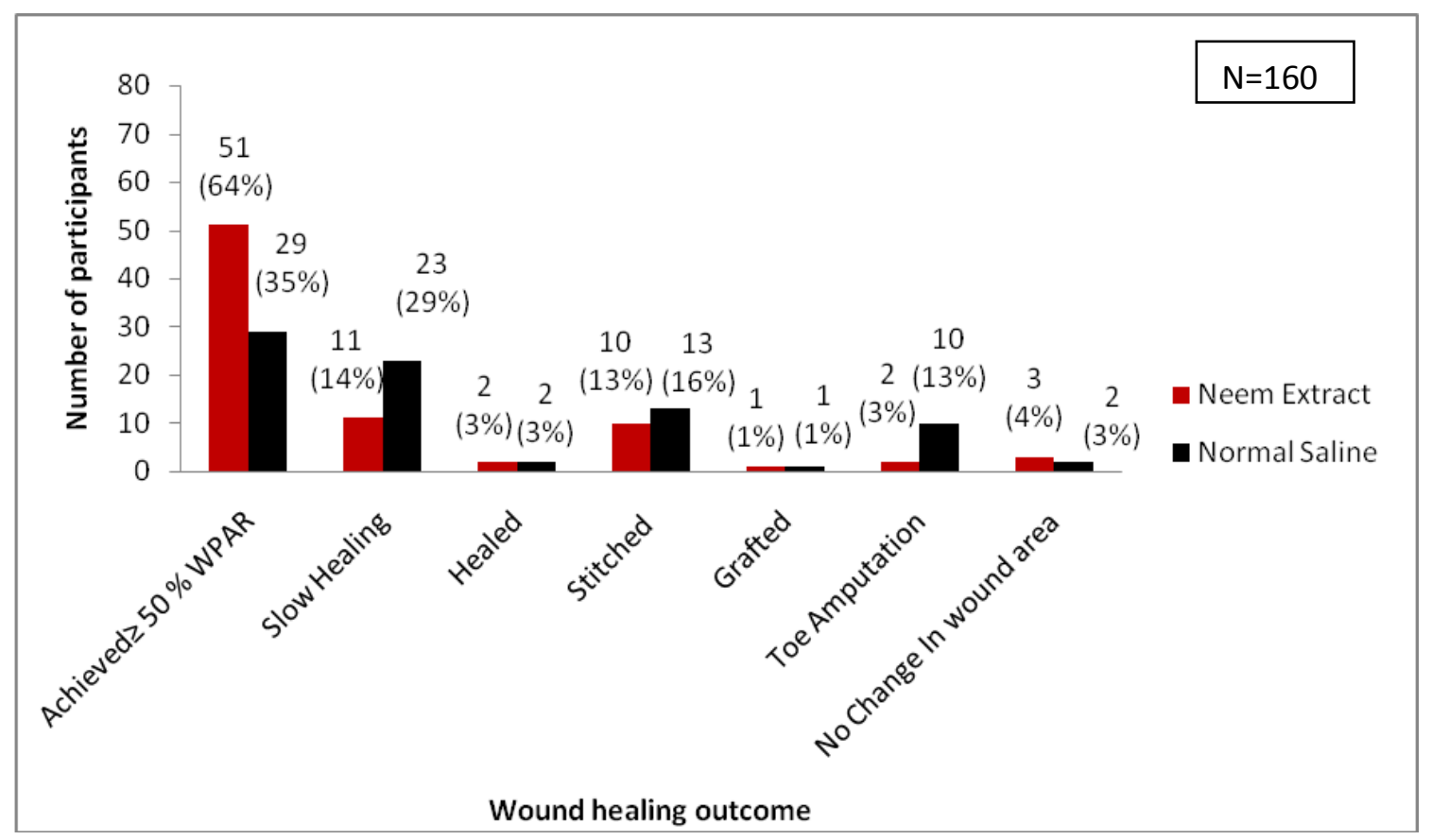

Figure 2: Wound Healing Outcome among Study Participants 
There were $50 \%(80 / 160)$ who achieved more than $50 \%$ wound area reduction at the end of 4 weeks together in both groups. Persistent unhealed outcome was observed in 2 patients. The other outcomes were recorded as wounds stitched (14 \%), underwent toe amputation $(8 \%)$ together in both groups. None of the patient underwent any major amputation during the study period.

\section{Wound care given:}

Patients underwent surgical debridement if required which was done by the treating surgeon. Wound was cleansed and irrigated with neem extract in one group and normal saline solution in another group. Dressing of the wound was done twice in a week for 4 week using topical antibiotic-povidone and covered with dressing materials. A secondary dressing was applied to cushion the wound for giving comfort. All patients followed off-loading technique as advised by the physician. Patient visited the clinic every 3-4 days, Wound was assessed for its size, tissue condition and exudate level till 4 weeks are completed.

\section{Wound Management outcomes:}

Healing outcomes at the end of 4 weeks were recorded on patients who participated in the study based on achievement wound area reduction and another outcome (Figure 2.).

\section{Discussion:}

Diabetic foot problems are responsible for $23-50 \%$ of the hospital bed occupancies by diabetic patients. ${ }^{[17]}$ The pooled worldwide prevalence of diabetic foot ulceration was
$6.3 \%(95 \% \mathrm{CI}: \quad 5.4-7.3 \%) .{ }^{[8]} \mathrm{DFU}$ are common occurrence in clinical practice with the lifetime risk of a patient with diabetes developing an ulcer may be as high as $25 \%$ during their lifetime. ${ }^{[14]}$ In Brazil, a higher frequency of DFU was observed among those who had an incomplete elementary schooling experience. ${ }^{[10]}$ In the current study $37.5 \%$ (60/160) patients had completed secondary school education, $26.25 \%$ were graduates and only $3.75 \%$ had no schooling. It is found that almost all the participants were not aware of self- foot care practices. This research study has shown that the length of time after diagnosis of diabetes mellites is associated with the risk levels of developing the DFU condition.

An ulcer present for more than 30 days is more likely to become infected. ${ }^{[15]}$ Throughout the world, it's estimated that every 30 seconds one leg is amputated due to diabetes. ${ }^{[18]}$ Infection is one of the leading causes of amputation due to diabetes-related foot ulcers. ${ }^{[16]}$ In the present study, clinical infection was present in $(92.8 \%)$ of all patients, gram-negative bacteria were the most commonly isolated in wound tissue culture. Klebsiella Pneumoniae was the most predominant anaerobic isolates, while Staphylococcus species was predominant in a tertiary care hospital in India. ${ }^{[20]}$

The physical examination of the patients' feet by a qualified professional is essential, since more than $10 \%$ of the participants described any sort of ulcerations of the lower limbs. ${ }^{[10]}$ The symptoms, such as "pain while walking," "rest pain", "muscle weakness," "cramps," or discomfort with the pressure of the blanket" may be suggestive 
of neuropathic and/or angiopathic alterations, which can be confirmed during neurological and vascular evaluations during physical examinations by a nurse. To diagnose Loss of protective sensation, (LOPS), vibratory sensations (using a tuning fork of $128 \mathrm{~Hz}$ ), was conducted according to present directives. ${ }^{[21]}$ The altered vibratory sensation, which was observed in $(42.5 \%)$ among both groups in this study, while study by Parisi et al demonstrated a statistically significant association with the risk of ulceration and amputation of the feet of DM patients. $^{\text {[22] }}$

In the present study, only $10 \%$ of the participants used appropriate footwear (diabetic shoe/sandal) and none of the patient presented with any foot deformity. In the study by Cubas et al. in Curitiba ${ }^{[23]}$ only $15 \%$ of the participants were observed to use appropriate footwear while in Brazil study $49.4 \%$ of the participants used appropriate footwear. $^{[10]}$ The present study identified that a frequency of $50 \%$ of patients in both groups had altered pulse palpation conditions suggesting PAD which supports a great number of Brazilian studies that rely only on pulse palpation, ${ }^{[10]}$ dorsalis pedis pulse is reported to be absent in $8.1 \%$ of healthy individuals, and the posterior tibial pulse is absent in $2.0 \%$. The absence of both pedal pulses, strongly suggest the presence of pedal vascular disease. ${ }^{[24]}$

More than $2 \%$ of community-based diabetic patients develop new foot ulcers each year. The neuropathy disability score, $10 \mathrm{~g}$ monofilament and palpation of foot pulses are recommended as screening tools in general practice. ${ }^{[25]}$ With regards to diabetes control, $81 \%$ of patients had poor glycemic control, i.e., HbAlc > 8\%. Poor drug compliance, lack of financial resources, and poor access to medical facilities may all compound this problem. ${ }^{[17]}$ The wjitcharoen et al. [26] in their study found that approximately $56.8 \%$ of DFU patients had neuropathy, while in our study $43.75 \%$ had any one of the neuropathy symptoms like numbness, pain, loss of vibration sensation. Almost all of our study participants were unaware about the self-foot care practices while $48.75 \%$ were unknown about their cause of the foot ulcers.

It is assumed that the main cause for progression of foot ulcers could be due to the co-existence of neuropathy and lack of knowledge on foot care practices. The majority $(60-80 \%)$ of foot ulcers will heal, while $10-15 \%$ of them will remain active, and $5-24 \%$ of them will finally lead to limb amputation within a period of 6-18 months after the first evaluation. ${ }^{[27]}$ The size of the wound also plays a critical role in prognosis, and a study showed that those with DFUs > $5 \mathrm{~cm}$ in diameter had poorer outcomes than those with smaller ulcers. ${ }^{[28]}$

The present study has found that the most common level of LEA was at the level of the toes $(6.87 \%)$ during the 4-week study period, while Indonesian study ${ }^{[17]}$ has found $67.2 \%$ and in Indian studies it was found 43.3 and $7.6 \%$. ${ }^{[29,30]}$ There were no patients who required major amputations in this study period of 4 weeks. In the current study, $1.8 \%$ only had undergone skin grafting while an Indian study reported that almost $52 \%$ of patients had split skin grafting. ${ }^{[31]}$ There was no change in wound 
size in 1.85 of study participants. This study could not establish between the dependent and independent variables due to the crosssectional design of the research and was limited to only 4 weeks of study period.

\section{Conclusion:}

The study identified that the loss of protective sensation could be a common cause of developing a foot ulcer. However, the risk factors that had a statistically significant association with the development of DFU were smoking habit, use of hypoglycemic agents. Ulcer grade and wound exudate are found to be associated with wound healing.

\section{Acknowledgements:}

Dr. Sudhir K. Jain, MBBS, MS, PhD, Director and Chief Foot Surgeon, Department of Diabetes Limb Complications and Foot Care, Sun valley Hospital and Research Unit, Guwahati, Assam.

\section{References:}

1. USAID/PHCPI \& Ministry of Health/ Iraq. Primary health care guidelines. 2013. www.urc-chs.com, October 2020

2. Wild S, Roglic G, Green A, Sicree R, King H. Global Prevalence of Diabetes: Estimates for the year 2000 and projections for 2030. Diabetes Care 2004; 27(5):1047-53.

3. Neel BA, Sargis RM. The Paradox of Progress: Environmental Disruption of Metabolism and the Diabetes Epidemic. Diabetes 2011; 60(7):1838-48.
4. Vijayakumar G, Manghat S, Vijayakumar R. et al. Incidence of type 2 diabetes mellitus and prediabetes in Kerala, India: results from a 10-year prospective cohort. BMC Public Health (2019) 19: 140.

5. Shahbazian H, Yazdanpanah L, Latifi SM. Risk assessment of patients with diabetes for foot ulcers according to risk classification consensus of international working group on diabetic foot. Pak J Med Sci 2013;29(3):730-734.

6. Chun D, Kim S, Kim J, Yang H-J, Kim $\mathrm{JH}$, Cho J, et al. Epidemiology and Burden of Diabetic Foot Ulcer and Peripheral Arterial Disease in Korea. JCM 2019; 8(5):748.

7. Ibrahim AM. Diabetic Foot Ulcer: Synopsis of the Epidemiology and Pathophysiology. International Journal of Diabetes and Endocrinology 2018; 3(2):23-28.

8. Zhang $\mathrm{P}$, Lu J, Jing $\mathrm{Y}$, Tang $\mathrm{S}$, Zhu D, Bi Y. Global epidemiology of diabetic foot ulceration: a systematic review and meta-analysis. Annals of Medicine 2017; 49(2) :106-16.

9. Raghav A, Khan ZA, Labala RK, Ahmad J, Noor S, Mishra BK. Financial burden of diabetic foot ulcers to world: a progressive topic to discuss always. Therapeutic Advances in Endocrinology 2018; 9(1):29-31. https://doi.org/10.1177/20420188177445 13.

10. Cardoso HC, Zara AL de SA, Rosa S de SRF, Rocha GA, Rocha JVC, Araújo MCE de, et al. Risk Factors and Diagnosis of Diabetic Foot Ulceration in 
Users of the Brazilian Public Health System. Journal of Diabetes Research, 2019: Article ID 5319892, pages 1-7.

11. Mohammad Z, Abida M, Jamal A. Diabetic Foot Ulcer: A Review. American Journal of Internal Medicine2015;3(2): 28-49.

12. Frykberg RG, Zgonis T, Armstrong DG, Driver VR, Giurini JM, Kravitz SR, Landsman AS, Lavery LA, Moore JC, Schuberth JM, Wukich DK, Andersen C, Vanore JV; American College of Foot and Ankle Surgeons. Diabetic foot disorders. A clinical practice guideline (2006 revision). J Foot Ankle Surg. 2006 Sep-Oct;45(5 Suppl): S1-66.

13. American Diabetes Association. Microvascular complications and foot care: Standards of Medical Care in Diabetes. Diabetes Care 2018; 41(Suppl. 1): S105-S118.

14. Boulton AJ, Vileikyte L, RagnarsonTennvall G, Apelqvist J. The global burden of diabetic foot disease. The Lancet 2005; 366(9498):1719-24.

15. Malhotra R, Chan CS-Y, Nather A. Osteomyelitis in the diabetic foot. Diabetic Foot \& Ankle 2014; 5(1):244 45.

16. Priyadarshini J, Abdi S, Metwaly A, AlLenjawi B, Jose JS, Mohamed H. Prevention of diabetic foot ulcers at primary care level. Dermatol Open J. 2018; 3(1): 4-9.

17. Pemayun TGD, Naibaho RM. Clinical profile and outcome of diabetic foot ulcer, a view from tertiary care hospital in Semarang, Indonesia. Diabetic Foot \& Ankle 2017; 8(1) ID:1312974.
18. www.england.nhs.uk/diabetes.com IDF Diabetes Atlas, 8th edn. Brussels, Belgium: International Diabetes Federation, 2017.

19. Van Netten JJ, Price PE, Lavery LA, Monteiro-Soares M, Rasmussen A, Jubiz Y, Bus SA; International Working Group on the Diabetic Foot. Prevention of foot ulcers in the at-risk patient with diabetes: a systematic review. Diabetes Metab Res Rev. 2016;32 Suppl 1:84-98.

20. Kavita AC, Ameeta A J, Seetala S, Renu SB, Irfana SM, Vibhavari SH, Shubhra SS. Bacteriological analysis of Diabetic foot infection. Bombay Hospital Journal 2011;53(4):706-711.

21. Khawaja N, Abu-Shennar J, Saleh M, Dahbour SS, Khader YS, Ajlouni KM. The prevalence and risk factors of peripheral neuropathy among patients with type 2 diabetes mellitus; the case of Jordan. Diabetol Metab Syndr 2018; 10(1):8.

22. Parisi MCR, Moura Neto A, Menezes FH, Gomes MB, Teixeira RM, de Oliveira JEP, et al. Baseline characteristics and risk factors for ulcer, amputation and severe neuropathy in diabetic foot at risk: the BRAZUPA study. Diabetol Metab Syndr 2016; $8(1): 25$.

23. Cubas MR et al. Diabetic foot: guidelines and knowledge about preventivecare. Fisioter. mov. [online]. 2 013; 26(3) :647-55.

24. International Best Practice Guidelines: Wound Management in Diabetic Foot Ulcers.Wounds International 2013. 
INTERNATIONAL JOURNAL OF AYUSH CASE REPORTS (IJA-CARE)

Available

from:

www.woundsinternational.com

25. Abbott CA, Carrington AL, Ashe H, Bath S, Every LC, Griffiths J, et al. The North-West Diabetes Foot Care Study: incidence of, and risk factors for, new diabetic foot ulceration in a communitybased patient cohort: Original article. Diabetic Medicine 2002; 19(5):377-84.

26. Thewjitcharoen Y, Krittiyawong S, Porramatikul S, Parksook W, Chatapat $\mathrm{L}$ Watchareejirachot $\mathrm{O}$, et al. Outcomes of hospitalized diabetic foot patients in a multi-disciplinary team setting: Thailand's experience. Journal of Clinical \& Translational Endocrinology 2014; 1(4) :187-91.

27. Alexiadou K, Doupis J. Management of Diabetic Foot Ulcers. Diabetes Ther 2012; 3:4.

28. Marzoq A, Shiaa N, Zaboon R, Baghlany Q, Alabbood MH. Assessment of the Outcome of Diabetic Foot Ulcers in Basrah, Southern Iraq: A Cohort Study. Int J Diabetes Metab 2019; 25:33-38.

29. Jain, A. and S, V. A study of diabetic foot patients in a tertiary care premier teaching hospital. International Journal of Surgery Science 2019; 3(1):183-187.
30. Nellaiappar P, Selvam AP, Sims S, Alfonso T. Surgical management of patients with diabetic foot ulcer (DFU) at a tertiary care hospital in Chennai, India. Global journal for research analysis 2018;7(10):8-10.

31. Jayalakshmi M. Dressing Methodology for Diabetic Foot Ulcers. International Journal of Nursing 2019;6(2):32-34.

Conflict of interest: Author declares that there is no conflict of interest.

Guarantor: Corresponding author is guarantor of this article and its contents.

\section{Source of support: None}

\section{How to cite this article:}

Jayalakshmi M, Thenmozhi P. Factors associated with wound healing outcome among Diabetic Foot Patients- A Cross Sectional Study. Int. J. AYUSH CaRe. 2021; 5(1): 36-46. 